Rakenteiden Mekaniikka (Journal of Structural Mechanics) vol. 53, nro 2, 2020, s. 53-66

http://rakenteidenmekaniikka.journal.fi/index

https://doi.org/10.23998/rm.83338

(C) 2020 kirjoittajat

Vapaasti saatavilla CC BY 4.0 -lisenssin mukaisesti

\title{
Käyräviivaiset koordinaatistot kontinuumimekaniikassa
}

\author{
Sami Holopainen ${ }^{1}$
}

Tiivistelmä Artikkelissa tarkastellaan suoraviivaisista avaruuskoordinaatistoista yleistettyjä käyräviivaisia koordinaatistoja ja niiden välisiä muunnoksia. Teoria esitetään suoraviivaisten koordinaatistojen teorian pohjalta. Yleistämisen keskeisenä ominaisuutena pidetään suoraviivaisten koordinaatistojen kantajärjestelmän yksikäsitteistä määrittelyä. Sovelluksina tarkastellaan kontinuumimekaniikan tärkeitä koordinaatistoja ja niiden välisiä muunnoksia, kannan vaihtoa, vaihdetun kannan derivaattoja sekä niissä tarvittavia niin kutsuttuja Christoffelin symboleja. Pohditaan myös mitä hyötyä käyräviivaisista koordinaatistoista ja niiden muunnoksista on.

Avainsanat: koordinaatistomuunnos, kantajärjestelmä, tensori, Christoffelin symbolit, deformaatio

Vastaanotettu: 26.6.2019. Hyväksytty: 25.10.2019. Julkaistu verkossa: 30.3.2020.

emeritusprofessori Tapio Salmen muistolle

\section{Johdanto}

Esitetty teksti esimerkkeineen perustuu osittain Tapio Salmen muistiinpanoihin ja hänen ennen julkaisemattomaan kirjalliseen materiaaliin, jonka hän lähetti allekirjoittaneelle (pyynnöstä) vuonna 2016. Tapio keskittyi opetuksen ohessa (johon hän ennenkaikkea panosti) kahteen eri tutkimusaiheeseen: koordinaatistoihin ja jännitys/venymämittoihin. Koska jälkimmäistä aihetta on jo aiemmin käsitelty ansiokkaasti Rakenteiden Mekaniikkalehden artikkeleissa [20, 21, 22] sekä [23], tässä artikkelissa keskitytään koordinaatistoihin.

Monet kontinuumimekaniikan tunnetut oppikirjat alkavat matematiikan peruskäsitteiden (vektori- ja tensorialgebra) esittelyllä, [1, 2, 3, 4, 5]. Esityksissä avaruuden koordinaatistot oletetaan yleisesti tunnetuksi, jolloin niitä ei ole tarkemmin määritelty. Poikkeuksetta koordinaatiston määrittely sivuutetaan täysin artikkeleissa (oletetaan suoraviivaiseksi, suorakulmaiseksi ja normeeratuksi; termit määritellään jäljempänä), [6, 7]. Lopulta kuitenkin, jotta tuloksia voidaan esittää tai (numeerisesti) laskemalla aikaansaada, koordinaatisto on määriteltävä. Tässä artikkelissa tarkastellaan suoraviivaisista avaruuskoordinaatistoista yleistettyjä käyräviivaisia koordinaatistoja ja niiden välisiä muunnoksia. Teoria esitetään suoraviivaisten koordinaatistojen teorian pohjalta. Avaruudella tarkoitetaan kolmiulotteista avaruutta, jossa on voimassa euklidinen geometria.

\footnotetext{
${ }^{1}$ Vastuullinen kirjoittaja: sami.holopainen@tuni.fi
} 
Koordinaatistojen muunnoksia tarvitaan, jotta eri koordinaatistoissa tehtyjä havaintoja voidaan vertailla keskenään. Absoluuttisesti parasta koordinaatistoa absoluuttisten totuuksien esittämiseksi ei yleensä tunneta. Riittää, että fysikaalinen yhtälö esittää absoluuttista totuutta kaikissa kysymykseen tulevissa koordinaatiston muunnoksissa: totuus ei muutu vaan pysyy invarianttina, [8] (ja Tapion muistiinpanot).

Koordinaatistoksi käy itse asiassa mikä tahansa sellainen sääntö, jonka mukaan avaruuden pisteet voidaan yksikäsitteisesti määrittää. Näin esitetty sääntö määrittelee koordinaatiston koko avaruutta tai sen osaa varten. Koordinaatiston muuntamisella toiseksi koordinaatistoksi tarkoitetaan edellä mainitun yksikäsitteisen säännön vaihtamista toiseen yksikäsitteiseen sääntöön (tietyin ehdoin). Artikkeli jatkuu koordinaatistojen konstruoimisella. Aihetta valaistaan valikoiduilla esimerkeillä. Artikkelin lopussa olevassa liitteessä muistellaan Tapio Salmea.

\section{Koordinaatistojen historiaa}

Vaikka koordinaatiston käsite on tunnettu vasta muutaman vuosisadan ajan, koordinaatistot ovat sinällään olleet implisiittisesti käytössä jo vuosituhansia: ihmisellä on ollut tarve muodostaa tietoa paikoista maanpinnalla ja tähtien sijainnista taivaankannella. Antiikin Kreikan tähtitieteilijä Hipparkhos (n. 190-120 eKr) esitti tähtiluettelossaan tähtien sijainnit taivaankannella kulmaetäisyyksinä, joita voidaan pitää tähtien koordinaatteina. Kolmesataa vuotta myöhemmin kreikkalainen Claudius Ptolemaios (n. 85-165 jKr) esitti pituus- ja leveysasteen paikan määrittämiseksi maan pinnalla. Pimeän keskiajan jälkeen ensimmäiset varsinaiset, suorakulmaiset koordinaatistot määritteli ranskalainen Rene Descartes (Discours de la Methode, v. 1637). Descartes oivalsi, että koordinaatisto toimii ainoastaan viitekehyksenä käyrälle eli sen luonne ei riipu valitusta koordinaatistosta. Tämän jälkeen lukuisat matemaatikot ja fyysikot ovat kehittäneet koordinaatistojen teoriaa. On luonnollista, että aihetta on sittemmin käsitelty myös kontinuumimekaniikassa, $[3,9,10,11,12,13,14]$.

\section{Kantajärjestelmä}

Avaruuskoordinaatisto muodostetaan valitsemalla joku avaruuden piste $O$ alkupisteeksi eli origoksi. Tässä rajoitutaan eukliidiseen avaruuteen $\mathrm{E}^{3}$, koska ihmiselle mielletyssä fysikaalisessa avaruudessa ei ole mitään absoluuttisesti parempaa avaruutta ja sen koordinaatistoja ${ }^{2}$. Koordinaatistoon kuuluu kolme origon kautta kulkevaa käyrää, jotka eivät ole samassa tasossa. Käyriä sanotaan koordinaatiston akseleiksi. Suoraviivaisessa (karteesisessa) koordinaatistossa käyrät ovat suoria. Jos akselisuorat ovat keskenään suorassa kulmassa, puhutaan suorakulmaisesta eli ortogonaalisesta koordinaatistosta. Jos akselisuorat ovat keskenään vinoja (ei suorakulmaisia), puhutaan vinokulmaisesta koordinaatistosta. Yleisemmin puhutaan käyräviivaisista koordinaatistoista. Kuvassa 1 esitetään origoon $O$ kuuluva suorakulmainen koordinaatisto $X^{1} X^{2} X^{3}$, piste $P$ ja siihen liittyvä niin kutsuttu paikkavektori

$$
\boldsymbol{r}=x^{1} \boldsymbol{e}_{1}+x^{2} \boldsymbol{e}_{2}+x^{3} \boldsymbol{e}_{3},
$$

jossa vektorit $x^{\mathrm{i}} \boldsymbol{e}_{\mathrm{i}}, \mathrm{i}=1,2,3$, ovat vektorin $\boldsymbol{r}$ (vektori)komponentit ja reaaliluvut $x^{\mathrm{i}}$ pisteen $P$ koordinaatit. Kuten on tavallista ja perusteltua määritellä, origon $O$ koordinaatit

\footnotetext{
${ }^{2}$ Maailmankaikkeutta ei nykyfysiikassa kuvata pelkästään euklidisella avaruudella, koska suhteellisuusteorian mukaisesti avaruuden rakenne taipuu suurilla nopeuksilla suurten massojen vaikutuksesta.
} 
ovat $x^{\mathrm{i}}=0$. Vektoreita $\boldsymbol{e}_{\mathrm{i}}$ sanotaan koordinaatiston $X^{1} X^{2} X^{3}$ kantavektoreiksi ja niiden yhdistelmä $\boldsymbol{e}_{1}, \boldsymbol{e}_{2}, \boldsymbol{e}_{3}$ muodostaa koordinaatiston kantajärjestelmän tai lyhyesti kannan. Normeeratun kannan kantavektoreille pätee $\left|\boldsymbol{e}_{\mathrm{i}}\right|=1$ (pituus on yksi).

Koordinaatiston kannalta edellytetään, että

1. kaikki origosta lähtevät avaruuden vektorit $\boldsymbol{r}$ voidaan esittää saman kannan avulla muodossa (1) ja

2. tämä esitys on yksikäsitteinen.

Voidaan osoittaa, että vektorikolmikko $\boldsymbol{v}_{1}, \boldsymbol{v}_{2}, \boldsymbol{v}_{3}$ kelpaa avaruuden kannaksi vain, kun vektorit ovat toisistaan lineaarisesti riippumattomia. Tämä tutkitaan toteamalla nk. Gramin matriisin

$$
\left[\begin{array}{ccc}
\boldsymbol{v}_{1} \cdot \boldsymbol{v}_{1} & \boldsymbol{v}_{1} \cdot \boldsymbol{v}_{2} & \boldsymbol{v}_{1} \cdot \boldsymbol{v}_{3} \\
\boldsymbol{v}_{2} \cdot \boldsymbol{v}_{1} & \boldsymbol{v}_{2} \cdot \boldsymbol{v}_{2} & \boldsymbol{v}_{2} \cdot \boldsymbol{v}_{3} \\
\boldsymbol{v}_{3} \cdot \boldsymbol{v}_{1} & \boldsymbol{v}_{3} \cdot \boldsymbol{v}_{2} & \boldsymbol{v}_{3} \cdot \boldsymbol{v}_{3}
\end{array}\right]
$$

determinantin arvo (nollasta poikkeava).

\section{Koordinaatiston muunnos}

Tutkitaan avaruuden pisteen $P$ koordinaattien $x^{\mathrm{i}}, \mathrm{i}=1,2,3$, kääntäen yksikäsitteistä eli käypää muunnosta

$$
\Gamma_{1}: y^{\mathrm{i}}=y^{\mathrm{i}}\left(x^{1}, x^{2}, x^{3}\right)
$$

koordinaatistosta $X^{1} X^{2} X^{3}$ koordinaatistoon $Y^{1} Y^{2} Y^{3}$, [15]. Muunnoksen osittaisderivaattojen muodostamaa matriisia

$$
\boldsymbol{J}:=\left[\begin{array}{lll}
\frac{\partial y^{1}}{\partial x^{1}} & \frac{\partial y^{1}}{\partial x^{2}} & \frac{\partial y^{1}}{\partial x^{3}} \\
\frac{\partial y^{2}}{\partial x^{1}} & \frac{\partial y^{2}}{\partial x^{2}} & \frac{\partial y^{2}}{\partial x^{3}} \\
\frac{\partial y^{3}}{\partial x^{1}} & \frac{\partial y^{3}}{\partial x^{2}} & \frac{\partial y^{3}}{\partial x^{3}}
\end{array}\right]
$$

sanotaan Jacobin matriisiksi ja sen determinantille käytetään merkintää $J$. Affiinimuunnoksessa

$$
y^{\mathrm{j}}=a_{\mathrm{i}}^{\mathrm{j}} x^{\mathrm{i}}+a^{\mathrm{j}}, i, j=1,2,3
$$

eli vektorimuodossa $\boldsymbol{y}=\boldsymbol{A} \boldsymbol{x}+\boldsymbol{a}, J$ on aina vakio. Voidaan osoittaa, että koordinaatiston affiinimuunnos on käypä, kun $J$ eroaa nollasta. Esitetty lause yleistyy myös epälineaarisille muunnoksille:

Olkoon epälineaarinen käypä muunnos $y^{\mathrm{i}}=y^{\mathrm{i}}\left(x^{1}, x^{2}, x^{3}\right)$ koordinaatistosta $X^{1} X^{2} X^{3}$ koordinaatistoon $Y^{1} Y^{2} Y^{3}$. Silloin on olemassa ominaisuudet:

1. $\boldsymbol{J} \neq \mathbf{0}\left(\boldsymbol{J}^{-1} \neq \mathbf{0}\right)$.

2. $\boldsymbol{J}^{-1}$ on identiteetti ja $\operatorname{det}\left(\boldsymbol{J} \boldsymbol{J}^{-1}\right)=1$.

3. $\operatorname{det}(\boldsymbol{J}) \neq 0$.

Toinen muunnos koordinaatistosta $Y^{1} Y^{2} Y^{3}$ koordinaatistoon $Z^{1} Z^{2} Z^{3}$ on $\Gamma_{2}: z^{\mathrm{j}}=$ $z^{\mathrm{j}}\left(y^{1}, y^{2}, y^{3}\right)$. Sitten saadaan

$$
z^{\mathrm{j}}=z^{\mathrm{j}}\left(y^{1}\left(x^{1}, x^{2}, x^{3}\right), y^{2}\left(x^{1}, x^{2}, x^{3}\right), y^{3}\left(x^{1}, x^{2}, x^{3}\right)\right),
$$

$\mathrm{j}=1,2,3$. Edelleen seuraava koordinaatiston muunnos on

$$
\Gamma_{3}=\Gamma_{2} \Gamma_{1}
$$


jne. Eli muunnosten muunnos on muunnosten yhdistetty kompositio (tulo). Soveltamalla ketjusääntöä (muunnokset ovat yksikäsitteiset ja jatkuvasti derivoituvat) saadaan,

$$
\frac{d z^{\mathrm{j}}}{d x^{\mathrm{k}}}=\frac{\partial z^{\mathrm{j}}}{\partial y^{\mathrm{i}}} \frac{\partial y^{\mathrm{i}}}{\partial x^{\mathrm{k}}}
$$

$\mathrm{j}, \mathrm{k}=1,2,3$ eli myös yhdistetty muunnos on jatkuva ja derivoituva. Näin voidaan jatkaa. Tästä seuraa seuraava tulos:

Koordinaatiston muunnoksen yleistetty kompositio on

$$
\Gamma=\Gamma_{\mathrm{n}} \Gamma_{\mathrm{n}-1} \ldots \Gamma_{2} \Gamma_{1} .
$$

Lisäksi yksikäsitteiselle muunnoksen kompositiolle on olemassa käänteismuunnos

$$
\Gamma^{-1}=\left(\Gamma_{\mathrm{n}} \Gamma_{\mathrm{n}-1} \ldots \Gamma_{2} \Gamma_{1}\right)^{-1}=\Gamma_{1}^{-1} \Gamma_{2}^{-1} \ldots \Gamma_{\mathrm{n}-1}^{-1} \Gamma_{\mathrm{n}}^{-1} .
$$

Eräitä käyräviivaisia koordinaatistoja on määritelty itsenäisesti ilman kytkentää jo olemassa oleviin koordinaatistoihin, kuten suoraviivaiseen koordinaatistoon. Tunnetuimpia, yleisestikin käytettyjä ovat sylinteri- ja pallokoordinaatistot. Itsenäisesti määritellyltä koordinaatistolta vaaditaan sen käypyyden toteamiseksi nk. käypyystesti. Testi on periaatteessa yksinkertainen:

1. koordinaatiston kanta täyttää edellä mainitut kaksi ehtoa ja

2. koordinaatistolla on käypä yhteys johonkin suoraviivaiseen koordinaatistoon. Koordinaatiston käypä yhteys tarkoittaa avaruuden pisteen $P$ kääntäen yksikäsitteistä eli käypää muunnosta:

$$
\Gamma: y^{\mathrm{i}}=y^{\mathrm{i}}\left(x^{1}, x^{2}, x^{3}\right) \text { and } \Gamma^{-1}: x^{\mathrm{j}}=x^{\mathrm{j}}\left(y^{1}, y^{2}, y^{3}\right), \mathrm{i}, \mathrm{j}=1,2,3 .
$$

Sylinteri- ja pallokoordinaatistot täyttävät käypyystestin. Voidaan myös rajoittua ainoastaan avaruuden osaan, jossa käyräviivainen koordinaatisto on käypä.

Esimerkki 1. Onko suoraviivaiselle ortogonaaliselle tasokoordinaatistolle $X^{1} X^{2}$ tehty muunnos

$$
y^{1}=x^{1}, y^{2}=x^{1}+\sinh \left(x^{2}\right)
$$

käyräviivaiseen koordinaatistoon $Y^{1} Y^{2}$ käypä?

Suoraviivaisen ortogonaalisen tasokoordinaatiston kanta on käypä ja muunnos on selvästikin määritelty koko tasossa. Tutkitaan muut käypyysehdot. Muunnos on yksikäsitteinen, jatkuva ja sillä on derivaatat

$$
\frac{\partial y^{1}}{\partial x^{1}}=1, \frac{\partial y^{1}}{\partial x^{2}}=0, \frac{\partial y^{2}}{\partial x^{1}}=1, \frac{\partial y^{2}}{\partial x^{2}}=\cosh \left(x^{2}\right)
$$

Ratkaisemalla kyseinen muunnos, saadaan

$$
x^{1}=y^{1}, x^{2}=\sinh ^{-1}\left(y^{2}-y^{1}\right)=\ln \left[\left(y^{2}-y^{1}\right)+\sqrt{\left(y^{2}-y^{1}\right)^{2}+1}\right] .
$$

Koska edellä olevat lausekkeet ovat yksikäsitteiset ja jatkuvat, esitetty muunnos on käypä.

Kuvassa 1 on esitetty esimerkin 1 koordinaattiakselit $X^{1}, X^{2}$ ja eräs hyperbolisen koordinaatiston verkosto.

Esitetty yksinkertainen muunnos jo osoittaa, että muunnokset ovat toinen toistaan numeerisesti tehokkaampia riippuen numeerisesta ratkaisimesta ja ohjelmointialustasta (kielestä). 

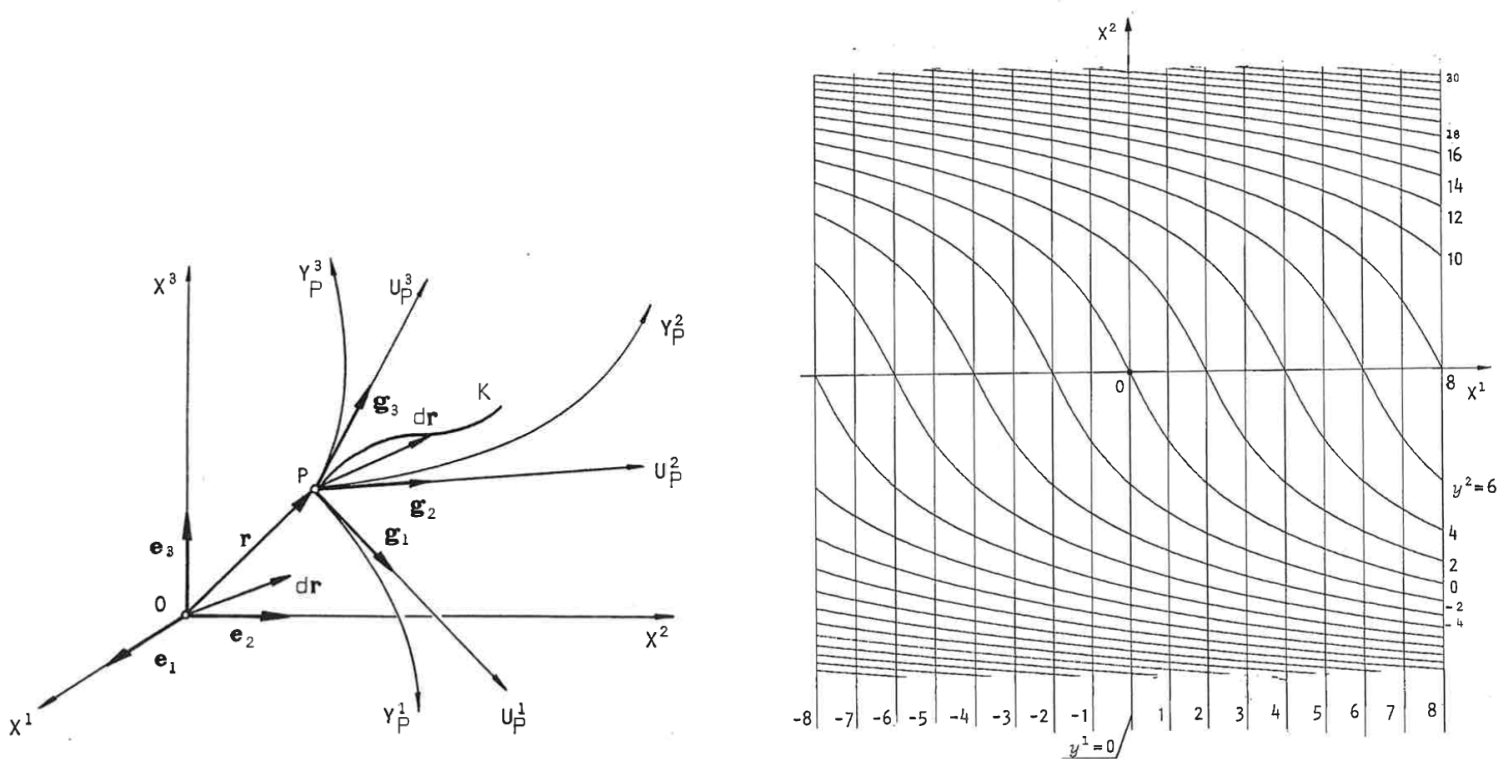

Kuva 1. Vasemmalla suorakulmainen koordinaatisto $X^{1} X^{2} X^{3}$, suoraviivainen lokaali tangenttikoordinaatisto $U_{\mathrm{P}}^{\mathrm{i}}$ sekä lokaaliset koordinaattiviivat $Y_{\mathrm{P}}^{\mathrm{i}}$. Globaali ja lokaali kanta on osoitettu vektoreilla $\boldsymbol{e}_{\mathrm{i}}$ ja $\boldsymbol{g}_{\mathrm{i}}, \mathrm{i}=1,2,3$. Oikealla hyperbelitasokoordinaatiston eräs verkosto.

\section{Kannan muuntaminen/vaihto}

Tarkastellaan suoraviivaisista avaruuskoordinaatistoista yleistettyjä käyräviivaisia koordinaatistoja. Yleistämisen keskeisenä ominaisuutena pidetään suoraviivaisten koordinaatistojen kantajärjestelmän yksikäsitteistä määrittelyä. Pidetään jatkossa kantaa $\boldsymbol{e}_{\mathrm{i}}, \mathrm{i}=1,2,3$, suoraviivaisena ja myös ortonormeerattuna. Siten paikkavektori (1) voidaan esittää

$$
\tilde{\boldsymbol{r}}=y^{1} \boldsymbol{e}_{1}+y^{2} \boldsymbol{e}_{2}+y^{3} \boldsymbol{e}_{3},
$$

missä $y^{\mathrm{i}}, i=1,2,3$ ovat vektorin (1) muunnetut koordinaatit. Esitetyt muunnokset siis jättävät avaruuden muuttumattomaksi.

Toisenlaisessa teoriassa kanta muuntuu: $\boldsymbol{e}_{\mathrm{i}} \rightarrow \boldsymbol{g}_{\mathrm{i}}$ ja koordinaatit eivät (konvektiivinen koordinaatisto). Myös sekä kanta että koordinaatit voivat muuntua, jolloin on olemassa sellaiset muunnokset, että $\boldsymbol{r}=$ $x^{1} \boldsymbol{e}_{1}+x^{2} \boldsymbol{e}_{2}+x^{3} \boldsymbol{e}_{3}=y^{1} \boldsymbol{g}_{1}+y^{2} \boldsymbol{g}_{2}+y^{3} \boldsymbol{g}_{3}$.

Kontinuumimekaniikan muodonmuutosten teoriassa muunnetut eli deformoituneet koordinaatit $y^{\mathrm{i}}$ tunnetaan Eulerin avaruudellisina koordinaatteina ja alkuperäiset koordinaatit (ei muodonmuutoksia) Lagrangen materiaalisina koordinaatteina. Konvektiivisessa koordinaatistossa niin kutsutun deformaatiogradientin komponenttimatriisi yhtyy identiteettimatriisiin (muodonmuutokseton alkutila), [3, Section 2.3].

Paikkavektori voidaan esittää myös muuttujiensa avulla:

$$
\left.\left.\tilde{\boldsymbol{r}}\left(x^{1}, x^{2}, x^{3}\right)=\tilde{\boldsymbol{r}}\left(y^{1}\left(x^{1}, x^{2}, x^{3}\right)\right), y^{2}\left(x^{1}, x^{2}, x^{3}\right)\right), y^{3}\left(x^{1}, x^{2}, x^{3}\right)\right) .
$$

Differentioimalla paikkavektorin lauseke saadaan

$$
d \boldsymbol{r}=\frac{\partial \boldsymbol{r}}{\partial y^{\mathrm{i}}} d y^{\mathrm{i}}, i=1,2,3,
$$

missä $\boldsymbol{g}_{\mathrm{i}}:=\partial \boldsymbol{r} / \partial y^{\mathrm{i}}$ merkitsee paikkavektorin muuttumisnopeutta koordinaattiviivan $Y_{\mathrm{P}}^{\mathrm{i}}$ suunnassa eli pisteeseen $P$ piirretyn tangentin suunnassa, Kuva 1. Esitetty relaatio on samalla muunnetun kantavektorin $\boldsymbol{g}_{\mathrm{i}}$ määritelmä. Kantavektori $\boldsymbol{g}_{\mathrm{i}}(P)$ on siis paikan funktio 
ja näin muodostettu kanta on ortogonaalinen. Ottamalla huomioon

$$
d x^{\mathrm{j}}=\frac{\partial x^{\mathrm{j}}}{\partial y^{\mathrm{i}}} d y^{\mathrm{i}}, i=1,2,3,
$$

saadaan

$$
d \boldsymbol{r}=\boldsymbol{g}_{\mathrm{i}} d y^{\mathrm{i}}=\boldsymbol{e}_{\mathrm{j}} d x^{\mathrm{j}}=\boldsymbol{e}_{\mathrm{j}} \frac{\partial x^{\mathrm{j}}}{\partial y^{\mathrm{i}}} d y^{\mathrm{i}}, i=1,2,3
$$

eli

$$
\boldsymbol{g}_{\mathrm{i}}=\frac{\partial x^{\mathrm{j}}}{\partial y^{\mathrm{i}}} \boldsymbol{e}_{\mathrm{j}}, i=1,2,3 .
$$

Tätä kantaa sanotaan varsinaiseksi kannaksi eli originaalikannaksi, [3, 16].

Resiprookkisen koordinaatiston kanta $\boldsymbol{g}^{\mathrm{j}}$ toteuttaa relaation

$$
\boldsymbol{g}_{\mathrm{i}} \cdot \boldsymbol{g}^{\mathrm{j}}=\delta_{\mathrm{i}}^{\mathrm{j}}
$$

missä $\delta_{i}^{j}$ on Kroneckerin delta. Käyttämällä lauseketta (2) relaatiossa (3) päädytään tulokseen

$$
\boldsymbol{g}^{\mathrm{i}}=\frac{\partial y^{\mathrm{i}}}{\partial x^{\mathrm{j}}} \boldsymbol{e}^{\mathrm{j}}, i=1,2,3
$$

Edelleen metriikkamatriisien komponentit määritellään seuraavasti:

$$
\boldsymbol{g}_{\mathrm{k}} \cdot \boldsymbol{g}_{\mathrm{l}}=g_{\mathrm{kl}}, \boldsymbol{g}^{\mathrm{k}} \cdot \boldsymbol{g}^{\mathrm{l}}=g^{\mathrm{kl}}
$$

Metriikkamatriisit ovat siis koordinaatistokohtaisia ja paikan funktioita. Varsinainen avaruuden euklidinen metriikka on koordinaatistosta riippumaton. Edelleen yhtälöistä (2) ja (4) yhtälössä (5) seuraa tulokset:

$$
g_{\mathrm{kl}}=\frac{\partial x^{\mathrm{i}}}{\partial y^{\mathrm{k}}} \frac{\partial x^{\mathrm{j}}}{\partial y^{\mathrm{l}}} e_{\mathrm{ij}}, g^{\mathrm{kl}}=\frac{\partial y^{\mathrm{k}}}{\partial x^{\mathrm{i}}} \frac{\partial y^{\mathrm{l}}}{\partial x^{\mathrm{j}}} e^{\mathrm{ij}}
$$

Koska kanta $\boldsymbol{e}_{\mathrm{i}}$ on oletettu suoraviivaiseksi ja ortonormeeratuksi, $e_{\mathrm{ij}}=e^{\mathrm{ij}}=1, i=j$ ja $e_{\mathrm{ij}}=e^{\mathrm{ij}}=0, i \neq j$.

Edelleen voidaan johtaa käyräviivaisen koordinaatiston kantavektoreiden pisteen $P$ indeksin nostamis- ja alentamissäännöt:

$$
\boldsymbol{g}^{\mathrm{i}}=g^{\mathrm{ij}} \boldsymbol{g}_{\mathrm{j}}, \boldsymbol{g}_{\mathrm{i}}=g_{\mathrm{ij}} \boldsymbol{g}^{\mathrm{j}}
$$

Tulos (7) on luonnollisesti voimassa suoraviivaisessa koordinaatistossa $\left(\boldsymbol{e}_{\mathrm{i}}\right)$. Erotuksena korostetaan, että $\boldsymbol{g}^{\mathrm{i}}$ ja $\boldsymbol{g}_{\text {i }}$ ovat paikan funktioita. Voidaan myös osoittaa, että seuraava tulos on voimassa:

Molemmilla metriikkamatriiseilla on ominaisuus

$$
\operatorname{det}\left(g_{\mathrm{ij}}\right)=: G>0, \operatorname{det}\left(g^{\mathrm{ij}}\right)=1 / G>0, \operatorname{det}\left(g_{\mathrm{ij}}\right) \operatorname{det}\left(g^{\mathrm{ij}}\right)=1
$$

$j a$

$$
g_{\mathrm{ij}} g^{\mathrm{jk}}=\delta_{\mathrm{i}}^{\mathrm{k}} .
$$

Loppupäätelmänä todetaan, että käyräviivaisten koordinaatistojen teoria on lokaalisti sama kuin suoraviivaisten. Ero on siis siinä, että käyräviivaisten koordinaatistojen vakiosuureet ovat paikan funktioita ja siten vain lokaalisti vakioita. Usein käyräviivainen koordinaatisto ja sen kanta samaistetaankin lokaaliksi koordinaatistoksi. 
Esimerkki 2. Olkoon sylinterikoordinaatiston $Y^{1} Y^{2} Y^{3}$ ja ortonormeeratun suoraviivaisen koordinaatiston $X^{1} X^{2} X^{3}$ välillä muunnos

$$
x^{1}=y^{1} \cos \left(y^{2}\right), x^{2}=y^{1} \sin \left(y^{2}\right), x^{3}=y^{3} .
$$

Määritellä̈̈n sylinterikoordinaatiston pisteeseen $P:\left(y^{1}, y^{2}, y^{3}\right)$ liittyvät kannat $\boldsymbol{g}_{\mathrm{i}}$ ja $\boldsymbol{g}^{\mathrm{i}}$ sekä metriikkamatriisit $g_{\mathrm{ij}}, g^{\mathrm{ij}}$.

Valitaan kuvassa 2 esitetty piste P. Valitussa alueessa muunnoksella ei ole singulaaripisteitä. Muunnoksen Jacobin matriisin alkiot ovat

$$
\begin{aligned}
& \frac{\partial x^{1}}{\partial y^{1}}=\cos \left(y^{2}\right), \frac{\partial x^{1}}{\partial y^{2}}=-y^{1} \sin \left(y^{2}\right), \frac{\partial x^{1}}{\partial y^{3}}=0, \\
& \frac{\partial x^{2}}{\partial y^{1}}=\sin \left(y^{2}\right), \frac{\partial x^{2}}{\partial y^{2}}=y^{1} \cos \left(y^{2}\right), \frac{\partial x^{2}}{\partial y^{3}}=0, \\
& \frac{\partial x^{3}}{\partial y^{1}}=0, \frac{\partial x^{3}}{\partial y^{2}}=0, \frac{\partial x^{3}}{\partial y^{3}}=1 .
\end{aligned}
$$

Soveltamalla tulosta (2) kantavektorien lausekkeet ovat

$$
\begin{aligned}
& \boldsymbol{g}_{1}=\frac{\partial x^{\mathrm{i}}}{\partial y^{1}} \boldsymbol{e}^{\mathrm{i}}=\cos \left(y^{2}\right) \boldsymbol{e}_{1}+\sin \left(y^{2}\right) \boldsymbol{e}_{2},\left\|\boldsymbol{g}_{1}\right\|=1 \\
& \boldsymbol{g}_{2}=\frac{\partial x^{\mathrm{i}}}{\partial y^{2}} \boldsymbol{e}^{\mathrm{i}}=-y^{1} \sin \left(y^{2}\right) \boldsymbol{e}_{1}+y^{1} \cos \left(y^{2}\right) \boldsymbol{e}_{2},\left\|\boldsymbol{g}_{2}\right\|=y^{1} \\
& \boldsymbol{g}_{3}=\frac{\partial x^{\mathrm{i}}}{\partial y^{3}} \boldsymbol{e}^{\mathrm{i}}=\boldsymbol{e}_{3},\left\|\boldsymbol{g}_{3}\right\|=1
\end{aligned}
$$

Kantavektorien suunnat on esitetty kuvassa 2. Edelleen Jacobin matriisi on

$$
J^{\mathrm{ij}}:=\frac{\partial x^{\mathrm{i}}}{\partial y^{j}}=\left[\begin{array}{ccc}
\cos \left(y^{2}\right) & -y^{1} \sin \left(y^{2}\right) & 0 \\
\sin \left(y^{2}\right) & y^{1} \cos \left(y^{2}\right) & 0 \\
0 & 0 & 1
\end{array}\right]
$$

ja sen kä̈̈nteismatriisi

$$
\left(J^{\mathrm{ij}}\right)^{-1}:=\left(\frac{\partial x^{\mathrm{i}}}{\partial y^{j}}\right)^{-1}=\frac{\partial y^{\mathrm{i}}}{\partial x^{j}}=\left[\begin{array}{ccc}
\cos \left(y^{2}\right) & \sin \left(y^{2}\right) & 0 \\
-\sin \left(y^{2}\right) / y^{1} & \cos \left(y^{2}\right) / y^{1} & 0 \\
0 & 0 & 1
\end{array}\right]
$$

Ottamalla käänteismatriisin komponentit saadaan

$$
\begin{aligned}
\boldsymbol{g}^{1} & =\frac{\partial y^{1}}{\partial x^{\mathrm{j}}} \boldsymbol{e}^{\mathrm{j}}=\cos \left(y^{2}\right) \boldsymbol{e}^{1}+\sin \left(y^{2}\right) \boldsymbol{e}^{2}, \\
\boldsymbol{g}^{2} & =\frac{\partial y^{2}}{\partial x^{\mathrm{j}}} \boldsymbol{e}^{\mathrm{j}}=-\sin \left(y^{2}\right) / y^{1} \boldsymbol{e}^{1}+\cos \left(y^{2}\right) / y^{1} \boldsymbol{e}^{2}, \\
\boldsymbol{g}^{3} & =\frac{\partial y^{3}}{\partial x^{\mathrm{j}}} \boldsymbol{e}^{\mathrm{j}}=\boldsymbol{e}^{3} .
\end{aligned}
$$

Koska nyt $e_{\mathrm{ij}}=e^{\mathrm{ij}}=1, i=j$, metriikkamatriisit ovat

$$
g_{\mathrm{ij}}:=\boldsymbol{g}_{\mathrm{i}} \cdot \boldsymbol{g}_{\mathrm{j}}=\left[\begin{array}{ccc}
1 & 0 & 0 \\
0 & \left(y^{1}\right)^{2} & 0 \\
0 & 0 & 1
\end{array}\right]
$$



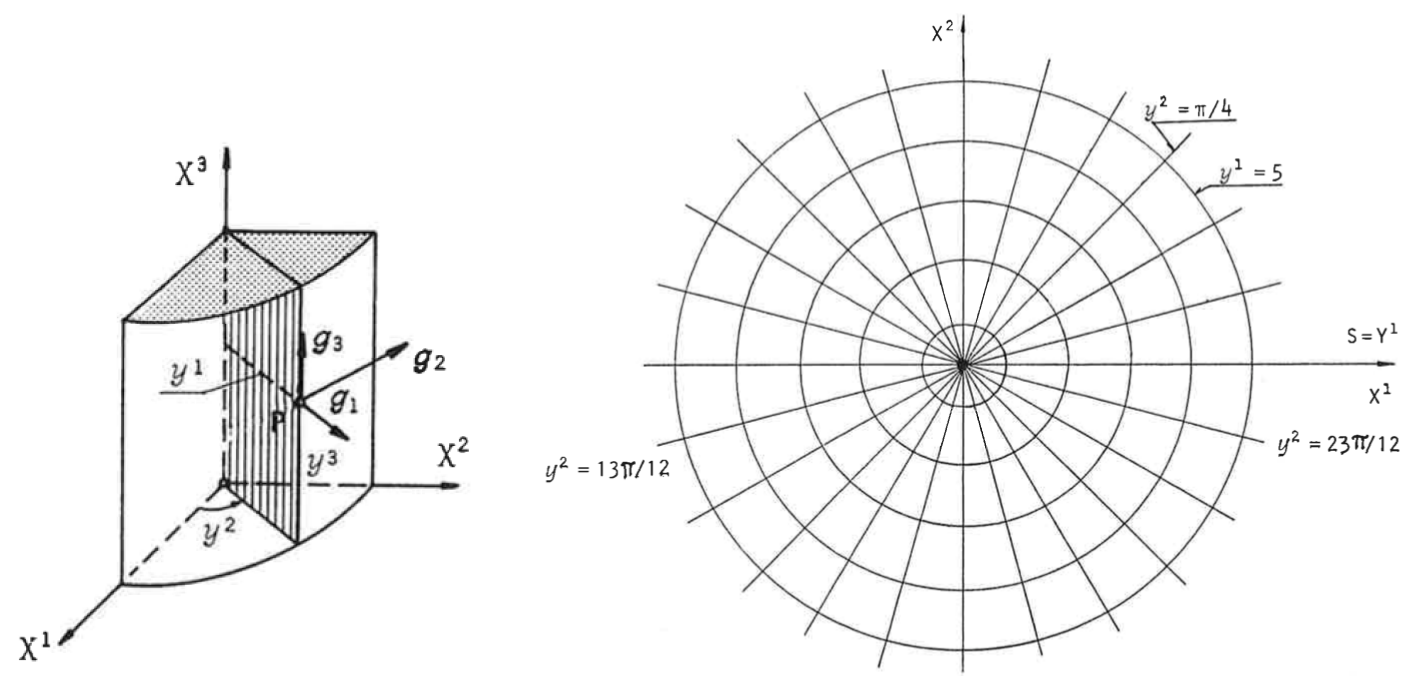

Kuva 2. Vasemmalla sylinterikoordinaatiston havainnollistus. Oikealla eräs napakoordinaatistoverkosto.

$j a$

$$
g^{\mathrm{ij}}:=\boldsymbol{g}^{\mathrm{i}} \cdot \boldsymbol{g}^{\mathrm{j}}=\left[\begin{array}{ccc}
1 & 0 & 0 \\
0 & 1 /\left(y^{1}\right)^{2} & 0 \\
0 & 0 & 1
\end{array}\right]
$$

eli $g_{\mathrm{ij}}=\left(g^{\mathrm{ij}}\right)^{-1}$, kuten pitääkin. Metriikkamatriisien determinatit ovat $G=\left(y^{1}\right)^{2}>0 \mathrm{ja}$ $G^{-1}=1 /\left(y^{1}\right)^{2}>0$.

Esimerkin 2 sylinterikoordinaatisto on havainnollistettu kuvassa 2. Samassa kuvassa on esitetty myös kontinuumimekaniikan tärkeä napakoordinaatistoverkosto, jossa koordinaatit $y^{1}$ ja $y^{2}$ muuttuvat vakiomäärällä napasäteen ja ympyräviivan suunnassa.

Suorakulmaiset käyräviivaiset koordinaatistot ovat sovellusten kannalta tärkeä ryhmä, koska niissä määritellyt tärkeät osittaisdifferentiaaliyhtälöt, kuten Laplacen ja Helmholzin yhtälöt, separoituvat. Niin kutsutut "klassiset" suorakulmaiset käyräviivaiset koordinaatistot ja niiden muodostamat verkostot voidaan järjestää seuraavasti:

1. Tasokoordinaatistot ja niiden verkostot: napa- ja kaksoisnapakoordinaatistot (tunnetaan myös polaarisina koordinaatistoina), elliptis-hyperbolinen koordinaatisto, parabolinen koordinaatisto;

2. Sylinterikoordinaatistot ja niiden verkostot: ympyräsylinterikoordinaatisto, elliptishyperbolinen sylinterikoordinaatisto, parabolinen sylinterikoordinaatisto;

3. Pallokoordinaatistot ja niiden verkostot: pallokoordinaatisto, yksivaippainen pallokoordinaatisto, kaksivaippainen pallokoordinaatisto.

4. Yleiset kartioleikkauskoordinaatistot ja niiden verkostot: kartiokoordinaatisto, ellipsoidikoordinaatisto, parapoloidinen koordinaatisto

5. Muut koordinaatistot ja niiden verkostot: kaksoispallokoordinaatisto, toroidinen koordinaatisto, parabolinen avaruuskoordinaatisto.

Edellä olevissa esimerkeissä esitettiin eräs tasokoordinaatiston hyperbolinen koordinaatisto sekä ympyräsylinterikoordinaatisto. Muita koordinaatistoja on käsitelty lähteissä, mm. [3, 5, 12, 17]. Edellä esitetty luokittelu perustuu Tapion muistiinpanoihin, joista löytyy esimerkkejä kaikista luokista. Erikseen on jälleen mainittava suorakulmainen ja suoraviivainen koordinaatisto, joka on yksinkertaisuutensa takia saavuttanut ehdottoman 
suosion kontinuumi- ja materiaalien mekaniikassa, [1, 2, 4, 14, 18].

\section{Koordinaatistoihin liittyvät Christoffelin symbolit}

Tarkastellaan käyvän muunnoksen $y^{\mathrm{i}}\left(x^{1}, x^{2}, x^{3}\right)$ määrittelemän $Y^{1} Y^{2} Y^{3}$-koordinaatiston kantoja $\boldsymbol{g}_{1}, \boldsymbol{g}_{2}, \boldsymbol{g}_{3}$ ja $\boldsymbol{g}^{1}, \boldsymbol{g}^{2}, \boldsymbol{g}^{3}$ sekä vastaavia metriikkamatriiseja $g_{\mathrm{ij}}$ ja $g^{\mathrm{ij}}$. Kantavektorin $\boldsymbol{g}_{\mathrm{i}}$ osittaisderivaatta yksityisen koordinaatin $y^{\mathrm{j}}$ suhteen on edelleen vektori ja se voidaan lausua mainittujen kantojen avulla muodoissa

$$
\frac{\partial \boldsymbol{g}_{\mathrm{i}}}{\partial y^{\mathrm{j}}}=: \alpha_{\mathrm{ijk}} \boldsymbol{g}^{\mathrm{k}}=\alpha_{\mathrm{ij}}^{\mathrm{k}} \boldsymbol{g}_{\mathrm{k}} .
$$

Muodostamalla sisätulo vektorin $\boldsymbol{g}_{1}$ kanssa saadaan

$$
\alpha_{\mathrm{ijk}} \boldsymbol{g}^{\mathrm{k}} \cdot \boldsymbol{g}_{1}=\alpha_{\mathrm{ijk}} \delta_{1}^{\mathrm{k}}=\alpha_{\mathrm{ij} 1}=\alpha_{\mathrm{ij}}^{\mathrm{k}} g_{\mathrm{k} 1} \Leftrightarrow \alpha_{\mathrm{ij}}^{\mathrm{k}}=g^{\mathrm{k} 1} \alpha_{\mathrm{ij} 1} \cdot
$$

Jos taas sisätulot muodostetaan vektorin $\boldsymbol{g}^{1}$ kanssa, saadaan

$$
\alpha_{\mathrm{ijk}}=g_{\mathrm{k} 1} \alpha_{\mathrm{ij}}^{1} \text {. }
$$

Muodostamalla lopuksi yhtälön (8) vasemman ja oikean puolen sisätulo vektorin $\boldsymbol{g}_{1}$ kanssa sekä vasemman puolen ja keskimmäisen osan sisätulo vektorin $\boldsymbol{g}^{1}$ kanssa, saadaan

$$
\alpha_{\mathrm{ijk}}=\frac{\partial \boldsymbol{g}_{\mathrm{i}}}{\partial y^{\mathrm{j}}} \cdot \boldsymbol{g}_{\mathrm{k}}, \alpha_{\mathrm{ij}}^{\mathrm{k}}=\frac{\partial \boldsymbol{g}_{\mathrm{i}}}{\partial y^{\mathrm{j}}} \cdot \boldsymbol{g}^{\mathrm{k}} .
$$

Määritelmä 1. Suure $\alpha_{\mathrm{ijk}}$ on Christoffelin 1. lajin (kolmi-indeksi)symboli ja suure $\alpha_{\mathrm{ij}}^{\mathrm{k}}$ Christoffelin 2. lajin (kolmi-indeksi)symboli ${ }^{3}$

Yhtälöistä (10) näkyy, että mainitut symbolit kytkeytyvät toisiinsa kolmanteen indeksiin nähden suoritetulla alentamis- tai nostamisoperaatiolla. Kahteen ensimmäiseen indeksiin tällaista operaatiota ei ole määritelty.

Voidaan osoittaa, että Christoffelin symboleilla on seuraavat symmetriaominaisuudet:

$$
\alpha_{\mathrm{ijk}}=\alpha_{\mathrm{jik}}, \quad \alpha_{\mathrm{ij}}^{\mathrm{k}}=\alpha_{\mathrm{ji}}^{\mathrm{k}} .
$$

Toinen, yleisempi tapa Christoffelin symbolien konstruoimiseksi tapahtuu derivoimalla metriikkamatriisin komponentit yhtälössä (5) yksittäisen koordinaatin $y^{1}$ suhteen:

$$
\frac{\partial g_{\mathrm{ij}}}{\partial y^{\mathrm{k}}}=\frac{\partial \boldsymbol{g}_{\mathrm{i}}}{\partial y^{\mathrm{k}}} \cdot \boldsymbol{g}_{\mathrm{j}}+\boldsymbol{g}_{\mathrm{i}} \cdot \frac{\partial \boldsymbol{g}_{\mathrm{j}}}{\partial y^{\mathrm{k}}}=\alpha_{\mathrm{ikj}}+\alpha_{\mathrm{jki}}
$$

Kun saatu reunimmainen yhtälö kirjoitetaan kolmesti suorittamalla samalla indeksien kierto, saadaan huomioimalla symmetria ominaisuudet (11) seuraavat tulokset

$$
\frac{\partial g_{\mathrm{ij}}}{\partial y^{\mathrm{k}}}=\alpha_{\mathrm{jki}}+\alpha_{\mathrm{kij}}, \frac{\partial g_{\mathrm{jk}}}{\partial y^{\mathrm{i}}}=\alpha_{\mathrm{ijk}}+\alpha_{\mathrm{kij}}, \frac{\partial g_{\mathrm{ki}}}{\partial y^{\mathrm{j}}}=\alpha_{\mathrm{ijk}}+\alpha_{\mathrm{jki}} .
$$

Vähentämällä ensimmäinen yhtälö kahden muun summasta saadaan

$$
2 \alpha_{\mathrm{ijk}}=\frac{\partial g_{\mathrm{jk}}}{\partial y^{\mathrm{i}}}+\frac{\partial g_{\mathrm{ki}}}{\partial y^{\mathrm{j}}}-\frac{\partial g_{\mathrm{ij}}}{\partial y^{\mathrm{k}}}
$$

\footnotetext{
${ }^{3}$ Christoffelin symboleja merkitään kirjallisuudessa eri tavoin. Yleisesti merkitään $[\mathrm{ij}, \mathrm{k}]=\alpha_{\mathrm{ijk}} \mathrm{ja}\left(\begin{array}{l}\mathrm{k} \\ \mathrm{ij}\end{array}\right)=$ $\alpha_{\mathrm{ij}}^{\mathrm{k}}$.
} 
Käyttämällä edelleen metriikkamatriisin komponenttien määrittelyä (5) ja kantavektorin indeksien nostamis- ja alentamissääntöjä (7), derivointi yksittäisen koordinaatin $y^{1}$ suhteen tuottaa lopulta

$$
\alpha_{\mathrm{ij}}^{\mathrm{k}}=g^{\mathrm{k} \alpha} \alpha_{\mathrm{ij} \alpha} .
$$

Derivoimalla yhtälö (3) yksittäisen koordinaatin $y^{1}$ suhteen, tuloksesta (8) seuraa

$$
\frac{\partial \boldsymbol{g}^{\mathrm{i}}}{\partial y^{\mathrm{j}}}=-\alpha_{\mathrm{jk}}^{\mathrm{i}} \boldsymbol{g}^{\mathrm{k}}
$$

Lause 1. Pätee relaatio $\frac{\partial g_{\mathrm{ij}}}{\partial y^{\mathrm{k}}}=\alpha_{\mathrm{ikj}}+\alpha_{\mathrm{jki}}$.

Todistus. Tuloksen (12) mukaan saadaan

$$
\alpha_{\mathrm{ikj}}+\alpha_{\mathrm{jki}}=\frac{1}{2}\left(\frac{\partial g_{\mathrm{kj}}}{\partial y^{\mathrm{i}}}+\frac{\partial g_{\mathrm{ij}}}{\partial y^{\mathrm{k}}}-\frac{\partial g_{\mathrm{ik}}}{\partial y^{\mathrm{j}}}\right)+\frac{1}{2}\left(\frac{\partial g_{\mathrm{ki}}}{\partial y^{\mathrm{j}}}+\frac{\partial g_{\mathrm{ji}}}{\partial y^{\mathrm{k}}}-\frac{\partial g_{\mathrm{jk}}}{\partial y^{\mathrm{i}}}\right)=\frac{\partial g_{\mathrm{ij}}}{\partial y^{\mathrm{k}}}
$$

Lauseesta 1 seuraa suoraan seuraava tulos.

Korollaari 1. Pätee relaatio $\frac{\partial g_{\mathrm{ij}}}{\partial y^{\mathrm{k}}}=g_{\mathrm{j} \alpha} \alpha_{\mathrm{ik}}^{\alpha}+g_{\mathrm{i} \alpha} \alpha_{\mathrm{jk}}^{\alpha}$.

Esimerkki 3. Esitetään sylinterikoordinaatiston pisteeseen P kuuluvat Christoffelin symbolit.

Ratkaisu. Esimerkin 2 tuloksena on saatu sylinterikoordinaatiston metriikkamatriisit $g_{\mathrm{ij}} \mathrm{ja} g^{\mathrm{ij}}$. Huomataan, että ainoa nollasta poikkeava metriikkamatriisin $g_{\mathrm{ij}}$ alkion osittaisderivaatta on

$$
\frac{\partial g_{22}}{\partial y^{1}}=2 y^{1}
$$

Tuloksesta (12) saadaan seuraavat nollasta poikkeavat alkiot

$$
\begin{gathered}
\alpha_{221}=\frac{1}{2}\left(\frac{\partial g_{21}}{\partial y^{2}}+\frac{\partial g_{21}}{\partial y^{2}}-\frac{\partial g_{22}}{\partial y^{1}}\right)=\frac{1}{2}\left(0+0-2 y^{1}\right)=-y^{1}, \\
\alpha_{122}=\frac{1}{2}\left(\frac{\partial g_{22}}{\partial y^{1}}+\frac{\partial g_{12}}{\partial y^{2}}-\frac{\partial g_{12}}{\partial y^{2}}\right)=\frac{1}{2}\left(2 y^{1}+0-0\right)=y^{1},
\end{gathered}
$$

kun muut alkiot ovat nollia. Tuloksesta (13) seuraa vastaavasti

$$
\begin{gathered}
\alpha_{22}^{1}=g^{11} \alpha_{221}+g^{12} \alpha_{222}+g^{13} \alpha_{223}=1 \cdot\left(-y^{1}\right)+0+0=-y^{1}, \\
\alpha_{12}^{2}=g^{21} \alpha_{121}+g^{22} \alpha_{122}+g^{23} \alpha_{123}=0+\frac{1}{\left(y^{1}\right)^{2}} y^{1}+0=\frac{1}{y^{1}} .
\end{gathered}
$$

Kaikilla muilla indeksien arvoryhmillä $\mathrm{i}, \mathrm{j}, \mathrm{k}$ alkio on nolla.

Esimerkki 4. Lasketaan funktion $\phi$ gradientti sylinterikoordinaatiston $Y^{1} Y^{2} Y^{3}$ pisteessä P, kun kannat ovat $\boldsymbol{g}_{1}, \boldsymbol{g}_{2}, \boldsymbol{g}_{3} j a \boldsymbol{g}^{1}, \boldsymbol{g}^{2}, \boldsymbol{g}^{3}$.

Ratkaisu. Gradientti määritellään kokonaisderivaatan avulla:

$$
\operatorname{grad} \phi=\frac{\partial \phi}{\partial y^{\mathrm{i}}} \boldsymbol{g}^{\mathrm{i}}=\frac{\partial \phi}{\partial y^{\mathrm{i}}} g^{\mathrm{ij}} \boldsymbol{g}_{\mathrm{j}}
$$

missä jälkimmäisessä tuloksessa sovellettiin indeksin alentamissääntöä (7). Käyttämällä Esimerkissä 2 laskettuja sylinterikoordinaatiston metriikkamatriiseja, saadaan

$$
\operatorname{grad} \phi=\frac{\partial \phi}{\partial y^{1}} \boldsymbol{g}_{1}+\frac{\partial \phi}{\partial y^{2}} \frac{1}{\left(y^{1}\right)^{2}} \boldsymbol{g}_{2}+\frac{\partial \phi}{\partial y^{3}} \boldsymbol{g}_{3} .
$$




\section{Päätelmät}

Artikkelissa on tarkasteltu suoraviivaisista avaruuskoordinaatistoista yleistettyjä käyräviivaisia koordinaatistoja ja niiden välisiä muunnoksia. Yleistämisen keskeisenä ominaisuutena on pidetty suoraviivaisten koordinaatistojen kantajärjestelmän yksikäsitteistä määrittelyä. Esimerkkeinä on tarkasteltu eräitä tunnettuja käyräviivaisia koordinaatistoja. Teoria esimerkkeineen osoittaa, että käyräviivaisilla koordiaatistoilla voidaan saavuttaa tiettyjä etuja:

1. koordinaatistojen väliset muunnokset ovat toinen toistaan numeerisesti tehokkaampia riippuen numeerisesta ratkaisimesta ja ohjelmointialustasta (kielestä);

2. käyräviivaiset suorakulmaiset koordinaatistot ovat sovellusten kannalta tärkeä ryhmä, koska niissä määritellyt tärkeät osittaisdifferentiaaliyhtälöt, kuten Laplacen ja Helmholzin yhtälöt, separoituvat;

3. suorakulmaisten ja käyräviivaisten koordinaatistojen väliset muunnokset voidaan kontinuumimekaniikan muodonmuutosten teoriassa tulkita epälineaarisiksi muodonmuutoksiksi;

4. epälineaaristen muodonmuutosten ja jännitysten lausekkeet yksinkertaistuvat ja ovat siten laskennallisesti tehokkaampia, kun käytetään sopivasti muodostettua epälineaarisen (käyräviivaisen) koordinaatiston kantaa.

Loppupäätelmänä myös todetaan, että käyräviivaisten koordinaatistojen teoria on lokaalisti sama kuin suoraviivaisten. Ero on siis siinä, että käyräviivaisten koordinaatistojen vakiosuureet ovat paikan funktioita ja siten vain lokaalisti vakioita. Usein käyräviivaista koordinaatistoa nimitetään siten lokaaliksi koordinaatistoksi. Tiettyjä lokaaleja suoraviivaisia koordinatistoja, kuten napa- tai polaarista koordinaatistoa, käytetään yleisesti numeerisissa ratkaisimissa, kuten kaupallisissa muodonmuutospohjaisissa elementtimenetelmäsovelluksissa. Sen sijaan käyräviivaisia koordinaatistoja epälineaaristen muodonmuutosten kuvaamiseen ei yleisesti ottaen ole sovellettu ratkaisimissa, vaikka käyräviivaisissa koordinaatistoissa muodostetut muodonmuutokset (muunnokset) voisivat tehostaa laskentaa. Tämä johtuu siitä, että suorakulmainen ja suoraviivainen koordinaatisto on kaikista yksinkertaisin.

Monia tärkeitä aiheita ei käsitelty tai niitä sivuttiin vain lyhyesti tässä artikkelissa:

1. Ortonormeerattujen koordinaatistojen ja sovellusten kannalta tärkeiden koordinaatistojen (esim. logaritmiset) väliset muunnokset;

2. Christoffelin symbolien muunnosominaisuudet;

3. Tensorifunktioiden tärkeät derivaattojen esitykset ((Leibnizin, Fréchetin) totaaliderivaatta, Gateaux- ja Lie-derivaatat) oleellisissa käyräviivaisten koordinaatistojen kannoissa;

4. Tärkeiden differentiaalioperaattoreiden esitykset (gradientti, divergenssi jne.) oleellisissa käyräviivaisten koordinaatistojen kannoissa;

5. Epälineaaristen muodonmuutosten ja jännitysten lausekkeiden yksinkertaistetut esitykset oleellisissa käyräviivaisten (epälineaaristen) ja konvektiivisten koordinaatistojen kannoissa.

Edellä mainittujen aiheiden selvittely kirkastaisi käyräviivaisten (epälineaaristen) ja konvektiivisten koordinaatistojen merkitystä kontinuumimekaniikassa.

\section{Viitteet}

[1] J. Bonnet and R. D. Wood. Nonlinear continuum mechanics for finite element analysis 2nd edition. Cambridge University Press, 2008. 
[2] T. Belytschko, W. K. Liu, and B. Moran. Nonlinear Finite Elements for Continua and Structures. John Wiley \& Sons, Chichester, 2000.

[3] Y. Basar and D. Weichert. Nonlinear Continuum Mechanics of Solids. Fundamental mathematical and physical concepts. Springer-Verlag, Berlin Heidelberg, 2000.

[4] G. A. Holzapfel. Nonlinear Solid Mechanics. A Continuum Approach for Engineering. John Wiley \& Sons, Chichester, 2001.

[5] M. Itskov. Tensor Algebra and Tensor Analysis for Engineers With Applications to Continuum Mechanics. Springer, New York, 2015.

[6] S. Holopainen, R. Kouhia, and T. Saksala. Continuum approach for modeling transversely isotropic high-cycle fatigue. European Journal of Mechanics A/Solids, 60:183195, 2016. Online:

https://doi.org/10.1016/j.euromechsol.2016.06.007

[7] S. Holopainen and T. Barriere. Modeling of mechanical behavior of amorphous solids undergoing fatigue loadings, with application to polymers. Computers and Structures, 199:57-73, 2018. Online:

https://doi.org/10.1016/j.compstruc.2018.01.010

[8] V. Huovinen. Havukka-Ahon ajattelija. WSOY, 1952.

[9] I. S. Sokolnikoff. Tensor Analysis. Theory and Applications. John Wiley \& Sons, New York, 1951.

[10] C. Truesdell and W. Noll. The Nonlinear Field Theories of Mechanics, Handbuch der Physik, Vol. III/3. Springer-Verlag, Berlin, 1965.

[11] W.H. Greub. Multilinear Algebra. Springer-Verlag, 1967.

[12] A. Borisenko and I. Tarapov. Vector and Tensor Analysis with Applications. PrenticeHall, New Jersey, 1968.

[13] R. Abraham, J. E. Marsden, and T. Ratiu. Manifolds, Tensor Analysis and Applications. Addison-Wesley, 1983.

[14] J. E. Marsden and T. J. R. Hughes. Mathematical Foundations of Elasticity. Dover publications, Inc., 1993.

[15] T. Apostol. Mathematical Analysis. Addison-Wesley, Lontoo, 1957.

[16] S. Holopainen. Representations of $m$-linear functions on tensor spaces. Duals and transpositions with applications in continuum mechanics. Mathematics and Mechanics of Solids, 19:168-193, 2014. Online: https://doi.org/10.1177/ 1081286512456199

[17] J. A. Schouten. Tensor Analysis for Physicists. Dover, New York, 1989.

[18] J. Gerdeen, H. Lord, and R. Rorrer. Engineering Design with Polymers and Composites. Taylor \& Francis, New York, 2006.

[19] I. Newton. Philosophice Naturalis Principia Mathematica (Principia). London, 1687. 
[20] J. Hartikainen, R. Kouhia, M. Mikkola, and J. Mäkinen. Muodonmuutoksen mitat kontinuumimekaniikassa. Rakenteiden Mekaniikka, 49:86-99, 2016. Online: http://rmseura.tkk.fi/rmlehti/2016/nro2/RakMek_49_2_2016_6.pdf

[21] M. Mikkola. Venymämitat kontinuumimekaniikassa Hillin-Sethin mukaan. Rakenteiden Mekaniikka, 50:1-16, 2017. Online: https://doi.org/10.23998/rm.63299

[22] M. Mikkola. Venymämitat kontinuumimekaniikassa Fingerin ja Piolan mukaan. Rakenteiden Mekaniikka, 50:451-462, 2017. Online: https://doi.org/10.23998/rm. 66414

[23] S. Holopainen. Alternative work conjugate pairs of stress and strain in simple shear. In 16th Nordic Seminar on Computational Mechanics (NSCM), 2003. https://www.researchgate.net/conference-event/NSCM_ Nordic-Seminar-on-Computational-Mechanics_2003/40301

Sami Holopainen

Tampereen yliopisto

s-posti: sami.holopainen@tuni.fi 


\section{Liite: Muisteluita}

Monet meistä muistavat Tapion Tappina, paitsi lupsakkana fudiksen ja salibandyn ystävänä, myös tinkimättömänä opettajana ja kontinuumimekaniikan tutkijana. Tapiolla oli käsittääkseni hallussa myös nykylatinan alkeet tai ainakin vanha englanti, ja hän perehtyikin moniin alkuperäisteoksiin, kuten itse Isaac Newtonin Principiaan, [19]. Hän kykeni esittämään mekaniikan periaatteet pelkistetysti oppikirjoissaan ja muistiinpanoissaan. Vertailua voidaan tehdä tämän artikkelin (perustuu Tapion muistiinpanoihin) ja viitteiden kesken, [9, 10, 11, 12, 13, 14].

Yhteistyö (vuosina 2003-08, 2011-12, toimin tutkijana Lundissa 2008-11) Tapion kanssa eteni seuraavasti: Tapio keksi esimerkin ja ratkaisi sen. Sen jälkeen hän pyysi ratkaisun allekirjoittaneelta ja joiltain muilta laitoksen tutkijoilta. Motivaationa oli usein $20 €$ palkkio. Esimerkit olivat haastavia ja muistelen tienanneeni noina vuosina yhteensä $40 €$. Mikäli ratkaisu yhtyi hänen omaansa, Tapio saattoi hyväksyä sen omiin muistiinpanoihinsa.

Läheisenä oppilaana ja työtoverina allekirjoittanut sai kokea myös Tapion ankaramman puolen (hän kirjoitti merkittävän osan tuotannostaan juuri noina vuosina ja oli ajoittain kireä). Esitellessäni nuorena yliopiston assistenttina (v. 2005, siihen aikaan vielä arvostettu opetusja tutkimusvirka) teoksen [3] kysymysten ratkaisuja (jatko-opinnot), Tapio menetti malttinsa; en ollut noudattanut hänelle olennaista Christoffelien symbolien indeksien alentamis- ja nostamissääntöä. Poistuin tuosta jatko-opintokuulustelusta korvat punaisina. Parin vuoden kuluttua (parin hylätyn uudelleen yrityksen jälkeen) Tapio kuitenkin yllättäen hyväksyi tuon jatkoopintokokonaisuuden korjauksineen jopa hieman kehuen. Lähestyvällä eläkeiällä ja keventyneellä työkuormalla saattoi olla vaikutusta.

Kuten usein oli tapana, istuimme iltapäiväkahvilla syksyllä 2012. Tapsa kertoili jälleen tensoreista ja yllättäen tituleerasi allekirjoittanutta Tensori-Samiksi erotuksena Iso-Samista (tunnetaan nimellä Sami Pajunen, nykyisin prof., Tampereen yliopisto). Tuo titteli, kaiken kritiikin ja sapiskan jälkeen, tuntui rehellisesti sanottuna hyvältä. Tapio arvosti paljon tohtorin tutkintoa; allekirjoittaneen väitöskirja oli hyväksytty vain hieman aikaisemmin.

Lopuksi pari sitaattia Tapiolta: "Ei riitä, että järki on terävä, tärkeintä on käyttää sitä oikein" (Rene Descartes, ranskalainen filosofi ja matemaatikko, jo v. 1596-1650); "Rakentamisessa ei taito ilman tietoa riitä"(Jean Mignot, n. v. 1400, Milano); "Kun osoitat kuuta, tyhmä katsoo sormea" (alkuperä ei ole allekirjoittaneen tiedossa).

Vaikka artikkeli on voimakkaasti tiivistetty kokooonpano Tapion muistiinpanoista ja käsittää lisäksi allekirjoittaneen omia muistiinpanoja, tekstissä on pyritty säilyttämään Tapiolle tärkeät asiat ja hänelle ominainen esitystapa. Myös esitetyt kuvat ovat suoria kopioita Tapion käsin piirtämistä originaaleista (tunnettiin taitavana piirtäjänä). 